14,17

\title{
Процессы самоорганизации в полисилоксановых блок-сополимерах, инициируемые модифицирующими добавками фуллерена
}

\author{
(С А.П. Возняковский ${ }^{1}$, В.Х. Кудоярова ${ }^{2}$, М.Ф. Кудояров ${ }^{2}$, М.Я. Патрова ${ }^{2}$ \\ ${ }^{1}$ Научно-исследовательский институт синтетического каучука им. акад. С.В. Лебедева, \\ Санкт-Петербург, Россия \\ ${ }^{2}$ Физико-технический институт им. А.Ф. Иофффе РАН, \\ Санкт-Петербург, Россия \\ E-mail: voznap@mail.ru
}

(Поступила в Редакцию 25 июля 2016 г.

В окончательной редакции 16 февраля 2017 г.)

\begin{abstract}
Методами атомно-силовой микроскопии, резерфордовского и нейтронного рассеяния изучены тонкие пленки полисилоксанового полиблочного блок-сополимера и их композитов с модифицирующей добавкой фуллерена $\mathrm{C}_{60}$. Методом атомно-силовой микроскопии показано, что при введении добавок фуллерена в объем полимерной матрицы первоначальный рельеф поверхности пленки нивелируется тем значительней, чем больше добавка. Такая тенденция связана с процессами самоорганизации последовательностей жесткого блока, которые инициируются полевым воздействием поверхности агрегатов фуллерена и приводят к росту числа их доменов в объеме полимерной матрицы. Данные резерфордовского и нейтронного рассеяния свидетельствуют о формировании дополнительных структур радиусом $60 \mathrm{~nm}$ только в пленках, содержащих фуллерен, причем их доля растет с увеличением концентрации фуллерена. Сопоставительный анализ данных этих методов показал, что такие структуры представляют собой именно домены жесткого блока и не формированы индивидуальными агрегатами фуллерена. Рассмотрена взаимосвязь структуры и механических свойств пленок полимера.
\end{abstract}

DOI: 10.21883/FTT.2017.08.44769.307

\section{1. Введение}

Тенденцией современного полимерного материаловедения является широкое использование аллотропных форм наноуглеродов в качестве модификатора полимерной матрицы с целью получения полимерных нанокомпозитов. Прежде всего, это связано с попытками выйти за рамки ограничений чисто синтетических возможностей получения материалов с улучшенным комплексом эксплуатационных параметров - достижением эффекта усиления (улучшения прочностных свойств полимерной матрицы) [1]. Под полимерными нанокомпозитами, как правило, понимают полимерные композиционные материалы, один или несколько компонентов которых имеют характерные размеры в нанометровом диапазоне [2,3]. Исходя из чисто феменологических рассуждений, за пороговое значение этого диапазона принимают характерный размер $\leq 100 \mathrm{~nm}[4,5,6]$.

При выборе в качестве наполнителя (модификатора) нанодисперсного вещества, как правило, отталкиваются от модельных представлений, связывающих уменьшение геометрических размеров частиц наполнителя с соответствующим ростом суммарной площади поверхности частиц и, как следствие, с ростом массовой доли межфазных слоев в полимерной матрице. Такие несколько упрощенные представления сталкиваются с экспериментально наблюдаемым различием влияния частиц наполнителей сопоставимой дисперсности, но различного происхождения (фуллерены, высокодисперсный оксид кремния, детонационные наноалмазы) на конечные свойства материалов [7,8]. Так, еще в работах Н.А. Ребиндера, опубликованных за период 1936-1941 гг. (например, [9]), было продемонстрировано, что не все высокодисперсные вещества с сопоставимой дисперсностью частиц приводят к реализации в полимерах одинакового эффекта структурообразования и соответственно эффекта усиления (улучшения прочностных свойств).

В настоящее время достижение эффекта усиления связывают не столько с дисперсностью частиц наполнителя, сколько с их удельной поверхностью и энергетическими характеристиками их поверхности. Следует отметить, что экспериментальная оценка поверхностной энергии нанодисперсных веществ представляет собой нетривиальную задачу. Существуют теоретические подходы к оценке поверхностной энергии нанодисперсных веществ. Так, в работах Магомедова, например [10], показано, что для нанокристаллов значение поверхностной энергии уменьшается с уменьшением размера нанокристалла. В работе [11] эти теоретические расчеты были подтверждены экспериментально.

Интуитивно невозможно предсказать, какие параметры полимерной матрицы изменятся наиболее значимо при введении в ее объем высокодисперсных частиц. Поэтому работы, посвященные изучению механизма усиления полимерной матрицы модифицирующими добавками высокодисперсных веществ, имеют не только теоретическое значение, но и несомненную практическую направленность. 


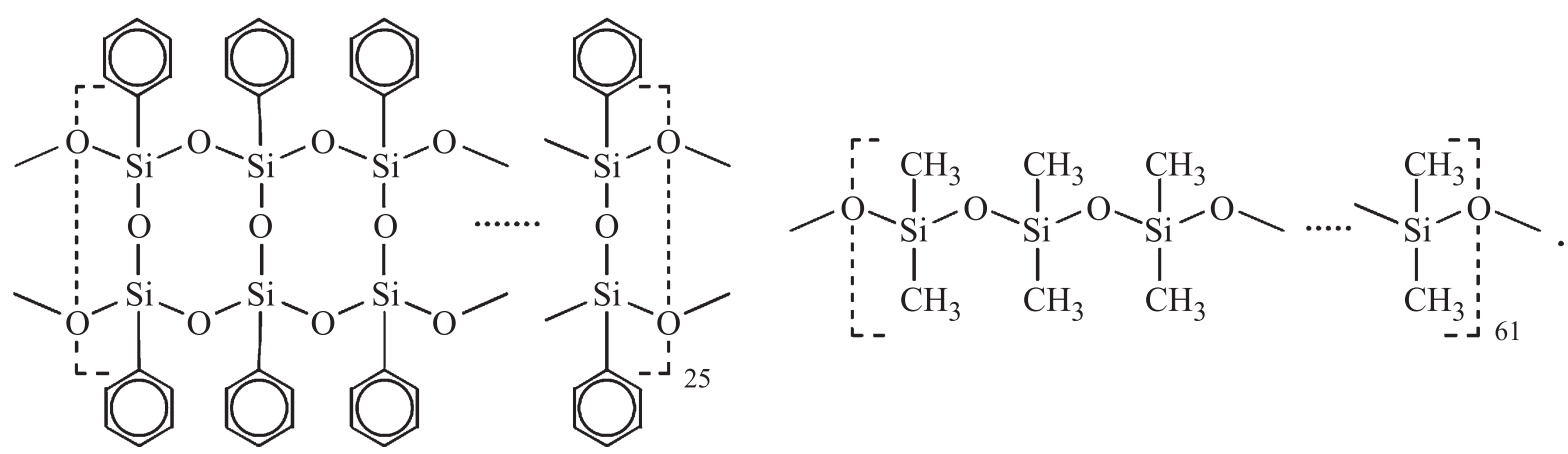

Pис. 1. Структурная формула полимера ЛФС-ПДМС.

В общем случае механизм усиления полимерной матрицы высокодисперсными веществами, прежде всего обусловлен формированием новых упорядоченных структур макроцепей как результат полевого воздействия поверхности частиц наполнителя. Однако как многообразие архитектуры полимерных молекул (гомополимеры, сополимеры, блок-сополимеры) и их химической природы (углеводородные, перфторированные, элементоорганические), так и многообразие форм высокодисперсных веществ дают ясное понимание сложности сведения взаимодействий полимер-наночастица к единому механизму. В полной мере это можно отнести и к доступным в настоящее время для полноценных лабораторных исследований наноуглеродам (фуллеренам, нанотрубкам, детонационным наноалмазам).

Среди эластомеров свойства кремнийорганических полимеров наиболее чувствительны к наполнению высокодисперсными наполнителями, поэтому они являются удобной моделью при изучении систем полимерная матрица-высокодисперсное вещество.

В настоящее время широкое практическое применение находят полиблочные полисилоксановые сополимеры типа $(A B)_{n}$, состоящие из жесткого с высокой температурой стеклования $(A)$ и гибкого $(B)$ полисилоксанового блоков. На их основе созданы пленкообразующие материалы с широким спектром потенциального применения - от протекторных покрытий до селективно-проницаемых мембран. Основное преимущество кремнийорганических блок-сополимеров перед гомополимерами заключается в том, что блок-сополимеры формируют так называемые „самоподдерживающиеся“ пленки (self-supporting films). Это различие обусловлено наличием узлов физической сетки, формирующейся в результате процессов самоорганизации последовательностей сомономера с большей величиной сегмента Куна [12].

Характерный пример полисилоксановых блок-сополимеров - полиблочный сополимер жесткого лестничного фенилсилсеквиоксана и гибкого полидиметилсилоксана (ЛФС-ПДМС). Для обеспечения формирования доменов жесткого блока в дисперсионной среде, диметилсилоксан при формировании реакционной массы берется в избытке.
Ранее [13] нами было изучено влияние на физикомеханические свойства пленок ЛФС-ПДМС ряда добавок высокодисперсных веществ: детонационных наноалмазов, детонационного углерода, высокодисперсной окиси кремния, стеклянных микросфер. Целью настоящей работы является исследование влияния модифицирующих добавок фуллерена $\mathrm{C}_{60}$ на физико-механические свойства пленок полисилоксанового полиблочного сополимера ЛФС-ПДМС.

\section{2. Экспериментальная часть}

2.1. Полимер. В качестве полимерной матрицы был выбран коммерческий ЛФС-ПДМС производства ФГУП НИИСК (Санкт-Петербург). Структурная формула полимера приведена на рис. 1. Соотношение длин последовательностей звеньев жесткого $(x)$ и гибкого $(y)$ блоков $x / y=25 / 61$. Массовая доля гибких ПДМС-блоков - 42.5\%.

2.2. Определение структуры растворов фуллеренов. Распределение частиц фуллеренов по размерам было изучено методом динамического рассеяния света на установке Coulter Counter (Beckman Coulter, France). Определялись параметры как среднечисленного, так и среднемассового распределения частиц фуллеренов $\mathrm{C}_{60}$ в неполярных средах.

Генератор ультразвука - установка Bransonic (Branson Co, Switzerland) ванного типа $(220 \mathrm{~V}, 50 \mathrm{~W})$ использовался для создания ультразвукового поля при формировании определенной дисперсности фуллеренов $\mathrm{C}_{60}$ в растворе.

2.3. Получение пленок полимеров. Перед использованием полученный полимер дважды переосаждали из раствора в толуоле этанолом. Навеску переосажденного полимера растворяли в толуоле. Отдельно готовили раствор расчетной навески фуллеренов в толуоле. В раствор полимера при постоянном интенсивном перемешивании последовательно добавляли раствор фуллерена и сшивающий агент. В качестве сшивающего агента использовали винилтрис(диметилкетоксиомо)силан (торговая марка „Винилоксим“, производство PENTA Co, Россия). 


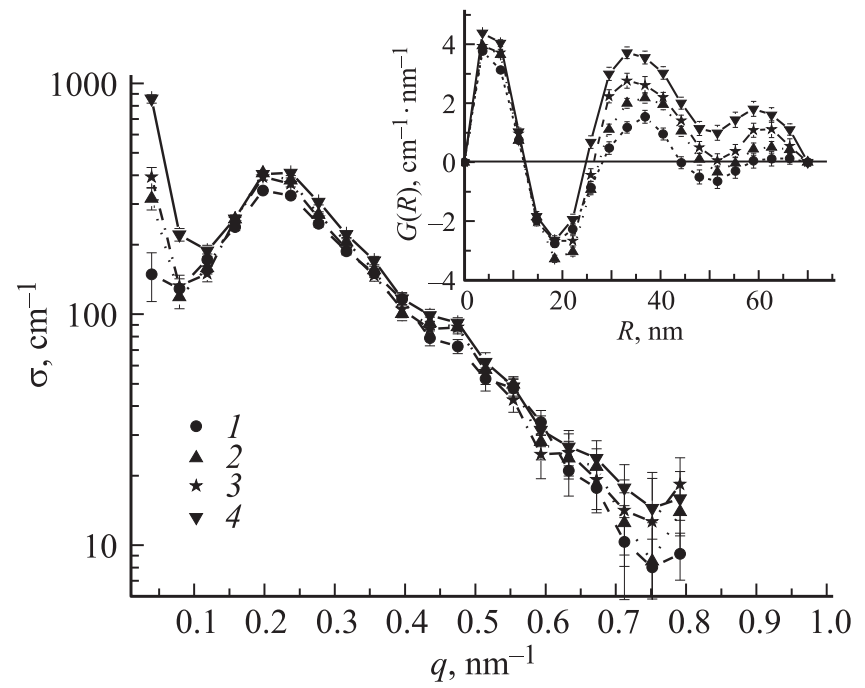

Рис. 2. Сечения малоуглового рассеяния нейтронов для образцов пленки ЛФС, содержащих фуллерен $\mathrm{C}_{60}$. Концентрация фуллерена, mass \%: $1-0,2-0.2,3-0.4,4-1$. Вставка: корреляционные функции $G(R)$ для исходной и модифицированных фуллереном пленок.

Полученный раствор переносили на целлофановую подложку и выпаривали под ИК-лампой при $40^{\circ} \mathrm{C}$ до исчезновения запаха растворителя. После этого полученная пленка снималась с целлофана и окончательно досушивалась в термостате при $170^{\circ} \mathrm{C}$ до постоянного веса.

2.4. Методы резерфордовского и нейтронного рассеяния. Образцы силоксановых пленок, содержащих фуллерен $\mathrm{C}_{60}$, были исследованы методом обратного резерфордовского рассеяния (ОРР) нейтронов с энергией $0.9 \mathrm{MeV}$ на электростатическом ускорителе ПИЯФ. Исследовались пленки полимера, содержание фуллеренов $\mathrm{C}_{60}$ в которых варьировалось от 0.1 до 1 mass $\%$.

Супрамолекулярная структура пленок исследовалась методом малоуглового рассеяния нейтронов в диапазоне переданных нейтронных импульсов $q=(4 \pi \lambda) \sin (\theta / 2)$ $=(0.03-0.8) \mathrm{nm}^{-1}$ на дифрактометре „Мембрана-2“ (длина волны $\lambda=0.3 \mathrm{~nm}, \Delta \lambda / \lambda=0.3$ ), установленном на реакторе VVP-M ПИЯФ. Рассеянные нейтроны регистрировались детектором, состоящим из $41^{3} \mathrm{He}$-счетчика в диапазоне углов $-2^{\circ} \leq 0 \leq 2^{\circ}$. Подробно метод малоуглового нейтронного рассеяния описан в [14].

Сечения рассеяния $\sigma(q)=d \sigma / d \Omega$ как функции переданного нейтронного импульса $q$ для исследованных пленок на единицу объема образца в единичный телесный угол $(\Omega)$ представлены на рис. 2. Они были получены из экспериментальных спектров с учетом фона и вклада прошедшего через образец пучка (трансмиссии) при нормировке данных на интенсивности рассеяния для стандартного образца известного сечения $\left(\mathrm{H}_{2} \mathrm{O} 1 \mathrm{~mm}\right)$. Представленная на вставке корреляционная функция $G(R)$ характеризует наличие и количество объемных структур, имеющих радиус $R$. Для исследованных образцов трансмиссия составляла 0.97 , что позволяло считать рассеяние практически однократным и пренебречь процессами многократного рассеяния.

2.5. Метод атомной силовой микроскопии. Измерения структуры пленок проводились в резонансном режиме на атомно-силовом микроскопе (АCM) „SOLVER P47-PRO“ с использованием кремниевых зондов NSG01.

2.6. Определение прочностных параметров. Прочностные свойства пленок исследовались на разрывной машине Н10КТ фирмы „Tinius Olsen“. Погрешность измерений составляла $1 \%$.

2.7. Сканирующая электронная микроскоп и я. Сканирующий электронный микроскоп Quanta 200 c приставкой EDAX использовался для анализа поверхности пленок и определения элементного состава исследуемого участка.

\section{3. Результаты и их обсуждение}

3.1. Формирование агрегатов $\mathrm{C}_{60}$ необходимой дисперсности. Ранее в работах [15-19] исследовалось влияние фуллерена $\mathrm{C}_{60}$ на физикомеханические параметры полимерной матрицы и продемонстрирована возможность достижения эффекта упрочнения. Тем не менее, модифицированные фуллереном пленки, приготовленные нами на первом этапе исследования, не показали преимущества по прочностным параметрам в сопоставлении с исходными пленками. Мы предположили, что высокая растворимость молекул фуллерена в толуоле (особенно при используемых нами низких концентрациях) приводит к распределению частиц, близкому к мономолекулярному, при котором не может быть сформирована хорошо организованная поверхность. Исходя из этого, на следующем этапе была проведена работа по снижению дисперсности частиц.

Ранее $[20,21]$ нами было показано, что структуры дисперсии наноуглеродов (растворов в случае фуллеренов) зависят от времени наложения ультразвукового (УЗ) поля. Так, может быть найдено оптимальное время выдержки в поле УЗ, при котором максимальная доля (по массе) частиц наноуглерода находится в нанодисперсном состоянии $(0-10 \mathrm{~nm})$. Следует, однако, учитывать, что в случае полимеров основной вклад в структуру, а соответственно и свойства полимерного материала, вносят межфазные взаимодействия. Теория высокодисперсных систем $[3,10]$ предсказывает, что определенной граничной поверхностью обладают не единичные частицы наноуглеродов (в нашем случае молекулы $\mathrm{C}_{60}$ ), а их агломераты. В этой связи, по нашему мнению, необходимо определить такое время выдержки в поле У3, при котором максимальная массовая доля $\mathrm{C}_{60}$ будет находиться в агломерированном состоянии.

Проведенные нами в соответствии с методикой, описанной в $[18,20]$, эксперименты показали, что оптимальное время выдержки толуольного раствора фуллерена в 
Таблица 1. Элементный состав и толщины исследованных пленок силоксана

\begin{tabular}{c|c|c|c|c|c}
\hline \multirow{2}{*}{ Образец } & \multirow{2}{*}{$\begin{array}{c}\text { Толщина, } \\
\mathrm{mm}\end{array}$} & \multicolumn{2}{|c|}{ Атомный состав (эксперимент) } & \multicolumn{2}{c}{$\begin{array}{c}\text { Концентрация } \\
\mathrm{C}_{60}, \text { таss } \% \text { (расчет) }\end{array}$} \\
\cline { 3 - 5 } & & кремний & кислород & углерод & 0 \\
Исходный & 0.1 & 1 & $1.04 \pm 0.02$ & $1.97 \pm 0.03$ & 0.2 \\
1 & 0.1 & 1 & $1.03 \pm 0.02$ & $1.99 \pm 0.03$ & 0.4 \\
2 & 0.1 & 1 & $1.04 \pm 0.02$ & $2.03 \pm 0.03$ & 1.0
\end{tabular}

Примечание. При расчете содержание кремния в молекуле взято за 1.

УЗ-поле составляет $20 \mathrm{~min}$. При этом массовая доля агломератов (частиц с диаметром в диапазоне $10-60 \mathrm{~nm}$ ) достигает $80 \%$. Методом динамического рассеяния была установлена стабильность структуры сформированных растворов фуллеренов в течение как минимум $3 \mathrm{~h}$, что вполне достаточно для приготовления композиционного материала.

3.2. Морфология пленок полимера, модифицированных фуллереном. Для того чтобы проследить, как влияет добавка фуллерена на надмолекулярную организацию тонких пленок полимера, модифицированного фуллереном $\mathrm{C}_{60}$, были проведены исследования на атомно-силовом микроскопе. На рис. 3 представлены АСМ топографии исходной полимерной пленки силоксана и пленки с добавлением $1 \% \mathrm{C}_{60}$ (вставка на рис. 3). Как можно заключить из анализа изображения на рис. 3 поверхность пленки характеризуется выраженной шероховатостью.

Полученные методом АСМ данные по влиянию содержания фуллерена на шероховатость пленки полимера представлены на рис. 4 (график 1). Так, измерения среднеквадратичной шероховатости (RMS - rootmean square deviation) показали, что введение фуллерена в по-

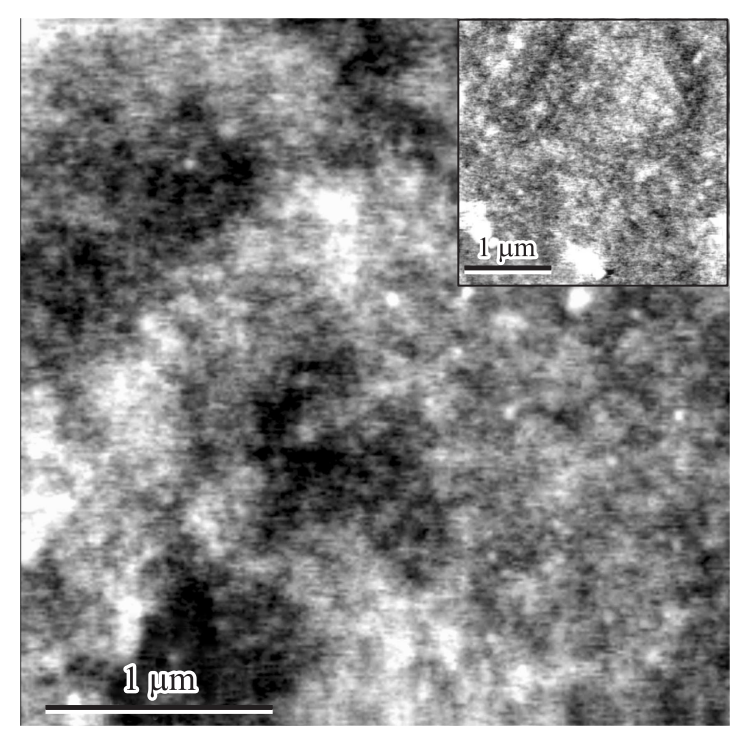

Рис. 3. АСМ-топография исходной полимерной пленки ЛФС-ПДМС без $\mathrm{C}_{60}$; вставка - полимерная пленка ЛФС-ПДМС с добавлением 1 mass\% $\mathrm{C}_{60}$.

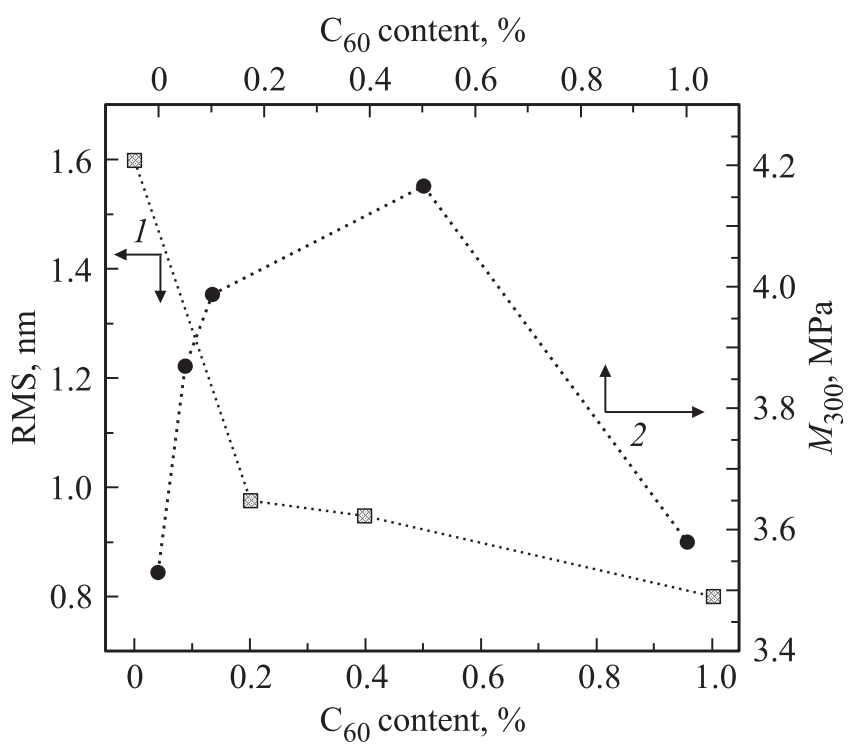

Рис. 4. Зависимость среднеквадратичной шероховатости RMS (1) и усиления сопротивления при 300\% деформации $M_{300}(2)$ от содержания $\mathrm{C}_{60}$ в пленках ЛФС.

лимерную матрицу уменьшает шероховатость поверхности от $1.6 \mathrm{~nm}$ в отсутствие $\mathrm{C}_{60}$ до $0.8 \mathrm{~nm}$ при содержании $\mathrm{C}_{60} 1 \%$, что свидетельствует об изменении морфологии полимера. Собственно, возникновение шероховатости для пленок исследуемого полимера можно связать со значительной разностью поверхностных энергий жесткого $\left(\sigma \approx 45 \cdot 10^{-3} \mathrm{~J} / \mathrm{m}^{2}\right)$ и гибкого $\left(\sigma \approx 20 \cdot 10-3 \mathrm{~J} / \mathrm{m}^{2}\right)$ блоков ЛФС [22].

С целью определения механизма влияния добавок фуллерена на морфологию тонких пленок полимера, они были исследованы методами обратного резерфордовского рассеяния (ОРР) и нейтронного рассеяния (НР). В табл. 1 приведены результаты исследования состава пленок методом ОРР.

Исследование состава и распределения элементов по глубине пленки позволяют заключить, что используемая методика формирования нанокомпозитов позволяет количественно вводить модифицирующие добавки фуллеренов, обеспечивая их равномерное распределение по объему полимерной матрицы.

Из спектров малоуглового рассеяния нейтронов (т. е. зависимости сечения рассеяния от импульса) для иссле- 
дуемых образцов, приведенных на рис. 2, видно, что в интервале радиусов до $70 \mathrm{~nm}$ в пленках наблюдаются рассеивающие структуры с радиусами $\sim 5, \sim 35$ и $\sim 60 \mathrm{~nm}$. Структуры с радиусом 5 и $35 \mathrm{~nm}$ присутствуют как в исходных (немодифицированных), так и в модифицированных фуллереном пленках блок-сополимера.

Структуры радиусом $60 \mathrm{~nm}$ появляются только в пленках, содержащих фуллерен, причем их доля растет с увеличением концентрации фуллеренов. Необходимо отметить, что источниками рассеяния в экспериментальном диапазоне импульсов могут быть как наноразмерные надмолекулярные структуры и неоднородности плотности самого силоксана, так и введенный $\mathrm{C}_{60}$ и его кластеры.

Таким образом, введение $\mathrm{C}_{60}$ приводит к изменению структуры: увеличению концентрации уже существующих рассеивающих центров и к появлению нового типа центров. Т.к. этот тип рассеивающих центров появляется при введении $\mathrm{C}_{60}$, а количество таких центров увеличивается с увеличением концентрации $\mathrm{C}_{60}$, можно было бы приписать его появление образованию кластеров фуллерена. Нами были проведены дополнительные исследования на сканирующем электронном микроскопе Quanta 200, имеющим приставку EDAX, которая позволила определить состав неоднородностей. Состав наблюдаемых неоднородностей не отличался от состава силоксана.

Следует отметить, что, изучая распределения фуллерена $\mathrm{C}_{60}$ в матрице чистой фазы полидиметилсилоксана, авторы работы [23] показали, что равномерного распределения $\mathrm{C}_{60}$ достичь не удается. Видимо, это связано с тем, что дисперсионная среда полиблочных полисилоксановых блок-сополимеров значительно отличается по составу от чистой фазы ПДМС. А именно, в дисперсионной среде полисилоксановых блок-сополимеров содержится значительное количество жестких блоков, не входящих в состав доменов [24].

3.3. Физико-механические испытания. Для проверки влияния массовой доли модифицирующей добавки фуллерена на прочностные свойства полимерной матрицы, были изготовлены пленки нанокомпозитов различного состава. Состав композитов и упругопрочностные параметры нанокомпозитов приведены в табл. 2. Как показывает анализ данных табл. 2, ввод модифицирующих добавок фуллерена в объем полимерной

Таблица 2. Влияние модифицирующих добавок фуллерена на прочностные параметры нанокомпозитов

\begin{tabular}{c|c|c|c|c}
\hline Концентрация & $M_{30}, \mathrm{MPa}$ & $M_{100}, \mathrm{MPa}$ & $M_{200}, \mathrm{MPa}$ & $M_{300}, \mathrm{MPa}$ \\
\hline 0.00 & 1.55 & 2.09 & 2.90 & 3.53 \\
0.05 & 2.11 & 2.52 & 3.24 & 3.87 \\
0.10 & 2.06 & 2.63 & 3.35 & 3.99 \\
0.50 & 2.26 & 2.72 & 3.50 & 4.17 \\
1.00 & 1.97 & 2.30 & 2.98 & 3.58
\end{tabular}

Примечание. $M$ - усилие, необходимое для деформации образца в процентах от исходного размера, индекс внизу — процент удлинения. матрицы, действительно, приводит к росту прочностных параметров полимерной матрицы при всех рассматриваемых деформациях. Следует также отметить, что значительное увеличение модифицирующих добавок (до 1 mass\%) практически приводит к параметрам, близким к ненаполненным образцам.

3.4. Построение модели усиления. Обратимся еще раз к рис. 4. Анализ представленных на рисунке данных (графики 1 и 2) показывает, что увеличение массовой доли фуллерена от 0.05 до 0.6 обусловливает две тенденции: снижение значений среднеквадратичной шероховатости и рост прочности пленок во всем интервале экспериментальных деформаций. При дальнейшем увеличении массовой доли $\mathrm{C}_{60}$ до $1 \%$ корреляция пропадает: снижаются как шероховатость, так и прочность пленки. Причем если шероховатость снижается незначительно, то прочность падает до величин, соответствующих ненаполненным пленкам. Данные резерфордовского и нейтронного рассеяния, дополняющие данные АCM, позволяют заключить, что центры рассеяния, в том числе центры, сформированные как результат введения фуллерена, расположены равномерно по всему объему полимерной матрицы. Ранее нами было показано, что супрамолекулярная структура ЛФС-ПДМС характеризуется наличием элементов свободного флуктуационного объема, равномерно распределенного по объему полимерной матрицы [25]. Таким образом, непротиворечиво можно предположить, что агрегаты молекул фуллерена преимущественно распределяются по элементам свободного объема полимера. Наноразмерные агломераты фуллерена координируют блоки жесткоцепного сомономера, находящиеся в окружающих макроцепях, формирующих дисперсионную среду. Эти процессы координации приводят к формированию новых узлов физической сетки и, соответственно, к росту прочностных параметров пленок [26].

Остановимся теперь на механизме снижения прочности при повышении концентрации фуллерена свыше 0.6 mass\%. Естественно предположить, что повышение концентрации фуллерена приводит к росту размера их агломератов до величин, заметно превышающих размеры элементов свободного флуктуационного объема. Таким образом, механизм распределения (растворения) агломератов $\mathrm{C}_{60}$ в матрице полимера меняется с клатратного на механизм замещения [27]. Вследствие ароматичности поверхности агрегатов фуллерена, они предпочтительно внедряются в области дисперсионной среды блок-сополимера, обогащенной жесткими блоками. Как следствие, создаются стерические препятствия процессам самоорганизации последовательностей жесткого блока, что отрицательно сказывается на формировании узлов физической сетки в полимерной матрице и соответственно на прочностных параметрах пленок.

\section{4. Выводы}

1. Установлено, что степень агрегации молекул $\mathrm{C}_{60}$ (при постоянной концентрации) в растворителе зависит от времени выдержки их раствора в поле ультразвука. 
2. Методом АСМ показано, что введение фуллерена в полимерную матрицу уменьшает шероховатость поверхности (от 1.6 до $0.8 \mathrm{~nm}$ ) с ростом содержания фуллерена в полимерной матрице (от 0 до $0.6 \%$ по массе).

3. Снижение шероховатости поверхности пленок может быть связано с инициированием процессов самоорганизации доменов жесткого блока при полевом воздействии поверхности агрегатов фуллерена $\mathrm{C}_{60}$. Этот процесс приводит к формированию дополнительных узлов физической сетки доменов жесткого блока и, как следствие, к более изотропной структуре поверхности пленки, что коррелирует с данными, полученными методами резерфордовского и нейтронного рассеяния.

4. Введение модифицирующих добавок фуллерена в объем полисилоксанового блок-сополимера приводит к заметному (до $80 \%$ ) росту прочностных параметров полученных пленок нанокомпозитов в сопоставлении с пленками ненаполненного полимера.

Авторы выражают благодарность В.Т. Лебедеву и В.М. Лебедеву за измерения и полезные обсуждения спектров малоуглового рассеяния нейтронов и Е.В. Гущиной за проведение АСМ-измерений.

\section{Список литературы}

[1] С.Т. Милейко. Композиты и наноструктуры 1, С. 6 (2009).

[2] D.R. Paul, L.M. Robeson. Polymer nanotechnology: Nanocomposites 49, 3187 (2008).

[3] L.A. Ovid'ko. Rev. Adv. Mater. Sci. 34, 9 (2013).

[4] V.N. Mochalin, Y. Gogotsi. Diamond Related Mater. 58, 9, 161 (2015).

[5] H. Gleiter. Prog. Mater. Sci. 33, 223 (1989).

[6] И.Д. Морохов, В.И. Петинов, Л.И. Трусов, В.Ф. Петрунин. УФН 133, 653 (1981).

[7] K. Chrissafis, K.M. Paraskevopoulos, I. Tsiaoussis, D. Bikiaris. J. Appl. Polymer Sci. 114, 1606 (2009).

[8] T.S. Volkova, A.Yu. Isaev, A.P. Petrova, P.L. Zhuravleva. Polymer Sci. D 6, 280 (2013).

[9] П.А. Ребиндер, Г.А. Аб, С.Я. Вейлер. ДАН СССР 31, 444 (1941).

[10] М.Н. Магомедов. ФТТ 46, 924 (2004).

[11] A.P. Voznyakovskii, M.F. Kudoyarov. Fullerenes, Nanotubes and Carbon Nanostructures 16, 644 (2008).

[12] А. Ношей, Д. Мак-Грат. Блок-сополимеры: Критический обзор. Мир, М. (1980). 478 c.

[13] A.P. Voznyakovskii. Phys. Solid State 46, 644 (2004).

[14] Д.И. Свергун, Л.А. Фейгин, Рентгеновское и нейтронное малоугловое рассеяние. Наука, М. (1986). 279 с.

[15] J.H. Jung, S. Vadahanambi, I.K. Oh. Composites Sci. Technology 70, 584 (2010).

[16] Б.М. Гинзбург, С.Х. Табаров, Ш. Туйчиев, А.А. Шепелевский. Письма в ЖТФ 33, 43 (2007).

[17] Sh. Tuichiev, S.Kh. Tabarov, B.M. Ginzburg. Technical Phys. 53, 956 (2008).

[18] V.V. Zuev, Y.G. Ivanova. Polymer Eng. Sci. 52, 1206 (2012).

[19] E. Badamshina, M. Gafurova. J. Mater. Chem. 22, 9427 (2012).

[20] A.P. Voznyakovskiǐ, M.F. Kudoyarov, M.Y. Patrova. Technical Phys. Lett. 33, 715, (2007).
[21] A.P. Voznyakovskii, M.F. Kudoyarov, O.F. Pozdnyakov. Technical Phys. Lett. 33, 865 (2007).

[22] В.П. Привалко. Свойства полимеров в блочном состоянии. Справочник по физической химии полимеров. Наук. думка, Киев, (1984). Т. 2. 330 с.

[23] A.A. Bogdanov, A.O. Pozdnyakov. Technical Phys. Lett. 42, 102 (2016).

[24] A.V. Kalinin, A.P. Voznyakovskiǐ. Phys. Solid State 51, 2409 (2009).

[25] A.P. Voznyakovskii, E.M. Krivoruchko. Polymer Sci. A 45, 157 (2003).

[26] А.Л. Свистков. Изв. РАН. Механика твердого тела 4, 82 (2010).

[27] Ю.А. Дядин. Соросовский образовательный журнал 2, 80, (1998). 